\title{
Calipedia moral, eugenesia estética y bellezas quirúrgicas: un post-racismo tecnomédico en las democracias liberales
}

\section{Moral caliper, eugenics and beautiful cosmetic surgery: A post-technomedical racism in liberal democracies}

\author{
Santiago Martínez-Magdalena \\ Universidad de Murcia, España. \\ santiago.magdalena@um.es
}

Recibido: 26-6-2014

Aceptado: 25-9-2014

\begin{abstract}
Resumen
Se repasan las relaciones establecidas por la cirugía estética y otras prácticas de belleza como instrumentos sociotécnicos mediadores en las supuestas exigencias de una sociedad democrático-liberal para superar un racismo que, de todos modos, es incapaz de abandonar el régimen escópico. Las intervenciones estéticas generarían una belleza específica, quirúrgica, universal y, por ende, post-racial. Esta pretensión, paradójicamente, acaba por ser posthumana y sitúa discursivamente equidistantes del centro argumental quirúrgico-estético, y como polos radicales, tanto al pensamiento raciológico-xenófobo como al progesista-emancipador, ambos conservadores respecto a la cirugía estética "democratizadora" de corte liberal.
\end{abstract}

Palabras clave: cirugía estética y cosmética, eugenesia estética, post-racismo liberal, régimen escópico.

\begin{abstract}
Relationships established for cosmetic surgery and other beauty practices as socio-technical instruments mediators in the alleged demands of a liberal democratic society to overcome racism that, however, is unable to leave the scopic regime are reviewed. The aesthetic interventions generate a specific, surgical, universal beauty and therefore postracial. This claim, paradoxically, ends up being post-human and discursively situated equidistant from surgical-center aesthetic argument, and as radical poles, both raciológico-xenophobic ideas as to progesista-emancipatory, both conservative regarding the "democratization" of cosmetic surgery liberal.
\end{abstract}

Key words: Aesthetic and Cosmetic Surgery, Aesthetic Eugenics, Post-liberal Racism, Scopic Regime.

Sumario

1. Introducción | 2. Cuerpo, rostro e identidad victimada | 3. La nariz mestiza y el balance facial: tras-lococorporizaciones de la identidad victimada| 4. El vaso expositivo de la centralidad escópica | 5 . La vulva pornográfica | 6. Conclusiones y perspectivas | Referencias bibliográficas 


\section{Introducción}

La cirugía estética es la vanguardia de un post-racismo médico con fundamento antropométrico e ideario social concreto que forma una entidad antropológica revitalizada. Se presenta como instancia de sanción del canon estético -que ha cambiado lo higiénico antes por lo estético ahora- al que contribuye decididamente, junto con la industria farmacéutica y cosmetológica, y trocando la frivolidad de la moda como motor de consumo por una necesidad en la sociedad de masas que permite "ser visto", entrar en el centro de la mirada, objetivarse en el deseo social, promocionarse y dirigir una autoidentidad ${ }^{1}$.

Las relaciones establecidas por la cirugía estética y otras prácticas de belleza pueden verse como instrumentos sociotécnicos mediadores en las supuestas exigencias de una sociedad democrático-liberal para superar un racismo que, de todos modos, es incapaz de abandonar el "régimen escópico" ${ }^{2}$ Las intervenciones estéticas generarían una belleza específica, quirúrgica, universal y, por ende, post-racial. Esta pretensión, paradójicamente, acaba por ser post-humana, aunque sitúa discursivamente equidistantes del centro argumental quirúrgico-estético, y como polos radicales, tanto al pensamiento raciológicoxenófobo como al postmoderno, ambos conservadores respecto a la cirugía estética "democratizadora" de corte liberal. Sin embargo, la asunción post-racista que descansa en la idea y la práctica sociomédicas reviste una calipedia moral $^{3}$ y una eugenesia estética conforme a un referente sospechoso: el canon caucásico (aparejado al estilo de vida anglosajón) como horizonte higiénico y normativo, la elección de modelos laborales (en tanto no se concluya la tarea de la ingeniería genética que proporcione esclavos genéticos $)^{4}$, y la exposición del cuerpo en el centro de la atención escópica. Su fundamento objetivador, de estirpe antropométrica, arrojaría dudas, por tanto, sobre su legitimidad argumental. Crearía diferencias (étnicas) primero (Wieviorka, 2003) para "corregirlas" después en la integración democrática de los cuerpos "aptos" para ser usados y mirados. Supone, además, el freno de la efectiva igualdad plural étnica, social y de género fundados en la diversidad igualitaria; es decir, del cumplimiento del proyecto modernizador en términos de igualdad sociojurídica, salvándolo a su vez por la única confianza en la tecnología médica como vanguardia sociológica (en la confianza de la elección racional promocionando por el cuerpo). Los debates trans- y post-, a su vez, han confundido, complicado, trasladado y ampliado las posibilidades identitarias y los espacios ideológicos y combativos entre el feminismo y el patriarcado, lo moderno y lo postmoderno, la igualdad, los derechos civiles y la libertad.

\section{Cuerpo, rostro e identidad victimada}

Frente a la mirada dominante en el régimen escópico que toma el objeto reificado en la centralidad de su retina, damos nuestro cuerpo como ganancia en la exposición. Una instrumentación que obedece a la violencia depredadora en la seguridad de la mirada voyeurista. Esta estrategia compromete la identidad que, aunque venga determinada por la exigencia del deseo de fuerza, es resistente y lo revierte: la

\footnotetext{
${ }^{1}$ La construcción identitaria dirigida, personal, que apenas puede escapar a la coacción y los dictados de la mirada social, donde más bien uno se viste y desviste, moldeando su cuerpo, sitúa en la centralidad de la mirada. Giddens (1994) entiende la autoidentidad como alejamiento de la naturaleza (externalizando la experiencia personal: la sexualidad se separa de la reproducción). El cuerpo y el self constituyen dos elementos recíprocos, pero sometiendo el primero, instrumentalmente, a la expresividad del segundo.

2 Jay (2003 y 2007) propone el término "Falogocularcentrismo" para denunciar el ocular-logo-centrismo (régimen escópico) como dominio fálico, que desde la seguridad de la distancia domina en la economía fetichista la cosa observada confiriéndole centralidad.

3 La Calipedia, entre la educación y la corrección física de los infantes, asume atribuciones morales de raíz presumiblemente física, por lo que no es extraño que tratados como el de A. Debay Hygiène et perfectionnement de la Beauté Humaine dans ses lignes, ses formes et sa cóuleur (Paris, 1864) recoja capítulos frenológicos y fisiognómicos.

${ }^{4}$ Habermas (2002) estima que la eugenesia liberal (intervención genética) liberaría al mercado de la oferta y demanda, equiparando eugenesia (dotación corporal) y educación (la eugenesia como educación ante-socializadora), dado que los hijos (personas preprogramadas) responderían a las necesidades laborales y sociales en su concepción paternal (a la discreción de un determinismo biológico dirigido) que llevaría a problemas identitarios y morales. Las consecuen cias de la crítica de Habermas para una antropología médica en torno a la cirugía puede seguirse Good (2003).
} 
identidad se concede como performance, permitiendo subjetividades paradójicas ${ }^{5}$. La importancia del rostro como (re-)presentación e identidad, máscara/persona y performance (reduciendo mucho al cuerpo, que pasa a ser extensión sexual), que asume la preeminencia representativa de la cara como afirmación de éxito social (blanca, simétrica y equilibrada, sonriente, sensual, peinada y maquillada), se exalta en la cirugía reparadora antes que en la estética. Los últimos logros en la cirugía reconstructiva de la cara (junto con la implantación de miembros como la mano o los trasplantes) y sus consecuencias sociales producen el efecto de "hacer público" al rostro, situándolo en el centro escópico. El primer trasplante de cara acarreó algunas consecuencias sociomediáticas: podemos ver a Isabelle Dinoire, primera persona con trasplante de cara, en una entrevista de prensa, relatando sus sensaciones y experiencias en la implantación de su nuevo rostro ${ }^{6}$. En portada, muestra como en una estereoscopia craneal sus perfiles fotográficos de frente, girando su cabeza desde una posición de espaldas, nuca y pelo, en actitud de recuperación o posesión de una cara (nueva). Los titulares son elocuentes: "Sin rostro no hay vida: el nuevo día a día de la primera persona con trasplante de cara". Se inicia su historia relatando el "horror" de la pérdida de su cara original: desmayada al tomar pastillas "para olvidar" sus problemas personales, su perro le comió parte de la cara. "Al despertar -recuerda-, llevé un cigarrillo, con un gesto automático, a mi boca. Era imposible. Se caía. Nada lo sostenía" (loc. cit.: 22). Se escenifica aquí la sordidez del cine negro. Del automatismo de la rutina se pasa entonces a la memoria activa del horror (perpetuo, irreparable, recordado y exhibido en el espejo) ${ }^{7}$. A partir de este horror se recurre a la ocultación de la cara perdida por medio de la máscara: "... este boquete me obligó a llevar una máscara durante seis meses para ocultar el espanto que yo suscitaba" (loc. cit.: 22). El horror portado provoca y proyecta un horror transmitido. Podía haberse sometido a la técnica tradicional del colgajo (estiramiento o traslado de piel próxima), evitando el rechazo de tejidos, "pero sólo habría tenido la apariencia de un rostro" (id.). Rostro, máscara, apariencia: una contradicción que encierra la tensión naturaleza/cultura (Vale Nieves, 2006-07) y que presume la extensión sociojurídica de la "persona". Porque Dinoire concluye: "Sin rostro no había vida posible" (loc. cit.: 23). Por otro lado, reconoce su inquietud frente a la publicación del rostro de la donante, el efecto mediático del antes y el después, o el ensoñado encuentro con los padres de la misma (ib.). La opinión pública supone en estos casos que la receptora va a heredar el rostro de la donante ( $y$, por sinécdoque, su personalidad usurpada), cuando en realidad se aprovecha el tejido blando que plásticamente se adapta a la estructura ósea de la receptora (Whitaker y Pertschuk, 1982; Clarke, y Butler, 2005; Sastré, 2007). No es un robo de identidad sino un préstamo de estructuras y tejidos, algo, de todas formas, que alimenta la discusión bioética (O'Neill y Godden, 2009), jurídica (Casa, 2007), y sobre identidad (Edgar, 2009) ${ }^{8}$. En Dinoire se establece un correlato entre la carne "creada de la carne" (en referencia a su madre) y la belleza del terso rostro nuevo aunque marcado por las cicatrices (recuerdo de la incisión sociotécnica) (loc. cit.: 23 y 24). Se compara con la donante: "Mi piel estaba lisa. La demarcación estaba ahí, claro, pero ambas teníamos la misma tez pálida" (ib.). Sin embargo, el rechazo no es sólo biológico, sino ajenidad psíquica y corporal, como es conocido en trasplantados a propósito de la falta de tersura: "En cambio, tenía extrañas sensaciones en la boca. Me daba asco sentir las paredes bucales de 'la otra', estaba blando, como un cuerpo extraño. Fue solo cuando empecé a moverla, a animar mis tejidos con la rehabilitación, que me hice con ella" (id.). Para actualizar la relación: "Le hice un sitio a mi donante en mi nuevo rostro. Somos dos y formamos una. Ni renuncio a mí

\footnotetext{
${ }^{5}$ La visión por internet de los tutoriales para conseguir un anime look de la niña-muñeca Dakota Rose Ostrenga (Kota Koti) es un ejemplo actual, en un juego entre el espejo de maquillaje que usa perceptiblemente (aunque invisible para nosotros) y la pantalla de internet por el que la vemos peinarse, y que termina con un "Thanks for watching" (Iranova, 2012). Por otra parte, las performance del hardcore y similares, con escenas de agresión sexual, devienen en cuestiones que no resuelven el problema de una victimología literal y parecen celebrar más bien el régimen escópico sin que censurarlas atente contra éste (más bien lo mantenga intacto). El trato de la mujer en el cine, por ejemplo, satisface la escopofilia de la mirada masculina: la erotización las hace "ser-para-ser-miradas" (Mulvey, 1991:436); y cuando es la mujer espectadora la que mira ese cine encuentra en él la norma vicaria de la feminidad que la compromete (De Lauretis, 1984:137).

${ }^{6}$ Seguimos El Semanal ( ${ }^{\circ} .1151,2009:$ 20-24).

${ }^{7}$ La importancia del espejo retorna cuando después del trasplante Dinoire explica: "Mirarme en el espejo se ha vuelto algo casi normal", "no llegaba a creer [cuando se miró al espejo] que habían conseguido cerrar 'mi agujero', me parecía milagroso" (loc. cit.: 23). El espejo es el trasunto social de la mirada que agrede: devuelve o entrega la sanción de la adecuación del sujeto sometido bajo la ideología calipédica.

${ }^{8}$ Es curioso comprobar cómo Sastré (2007) pone como ejemplo la cirugía estética con pacientes de disimulo étnico para demostrar que el trasplante de cara no cambia la fisonomía original del trasplantado.
} 
misma ni la aparto. Al morir ella me salvó a mí ${ }^{9}$. Es como una hermana. Al principio tenía incluso miedo de hacerle daño, de estropearla....; casi una convivencia". Una relación triple, con un nuevo personaje proyectado a partir de los otros dos, en la comparación de la vieja Isabelle con la nueva: "Tengo la impresión de que me salva psicológicamente mirar así [en el espejo] la nueva Isabelle" (id.). También es precisa la contradicción en la explicación de la necesidad/utilidad de su nuevo rostro, su feminidad y el contexto social hegemónico: "Pienso que quizá haya que ser mujer para no tener la menor duda [en trasplantarse]: la relación con nuestra imagen está tan íntimamente unida a nuestro sentimiento de feminidad que estamos dispuestas a todo para recuperarla" (loc. cit.: 23). Pone la necesidad reconstructiva en estética, en un sometimiento de la mujer que excusa la intervención en términos puramente estéticos como premisa biológica (Vale Nieves, 2006-07). Parece la feminidad aquí un subjetivismo estético: "[Todo ha vuelto a la normalidad (cfr. Davis, 2007: 20), como mirarse en el espejo:] Me pinto, me pongo maquillaje para atenuar la cicatriz, y máscara en las pestañas. Pero nunca me pinto los labios, porque debo hidratarlos continuamente. En realidad, no me veo tan mal" (loc. cit.: 24). Más adelante se pregunta por la incógnita del envejecimiento de su nueva piel. Dinoire continúa cuando en la entrevista se le pregunta por "los hombres", disculpándolos: "Ahora vivo sola. Los hombres no constituyen una prioridad para mí. Además, ¿quién me querría con este rostro? Fue lo que dije después de mi intervención, y lo sigo pensado" (loc. cit.: 23). La trascendencia del rostro en Dinoire se muestra al guardar su antiguo DNI, su "rostro de antes". Sacar fotos para el pasaporte fue "como renegar de la otra Isabelle": "No consigo enterrarla ni lo quiero. ¿Quién puede hacerme creer que ya no existo? Por eso me agarro a las viejas fotos. Es el único testimonio de lo que fui. He pedido a mis familiares todas las fotos... que tuvieran y siempre llevo algunas... Si algún día las perdiera, me volvería loca" (loc. cit.: 24$)^{10}$.

La importancia del rostro y el cráneo tuvo su impronta antropológica en la fisiognómica, la frenología y la ciencia forense (Caro Baroja, 1995). Los procedimientos para la identidad de los nacionales y las preocupaciones administrativas para la prevención de la delincuencia fueron a la par del desarrollo antropométrico ${ }^{11}$.

El marcado categorial por el físico (junto con la lengua, el vestido, la filiación...) constituye un referente grueso de la distinción racial y la clase (Bourdieu, 1998). De ahí la necesidad social de mantener "blanco" el origen, algo conocido desde antiguo, pero también en relación con el estigma de la enfermedad o el accidente deformante de la cara (Goffman, 2003). Estas necesidades de "blanqueamiento social por el físico", unidas a la de promoción laboral, sobre todo para el caso de la incorporación de las mujeres y los inmigrantes al mercado laboral (Wolf, 1991) ${ }^{12}$, han permitido justificar la intervención del cuerpo y la cara como presentación por excelencia con técnicas de disimulo, ocultación e integración social, religiosa o política. La duda se crea, no obstante, al sostener la tensión de verlas como procesos de resistencia estratégica o como superposición sociomédica ${ }^{13}$. En la historia médico-jurídica (MartínezPereda, 1997: 168 ss.) se representa la oposición de la ciencia médica con los poderes religiosos como

\footnotetext{
${ }^{9}$ Como si en una filiación bastarda la herencia ilegítima se compusiera en el compromiso social del parentesco político.

${ }^{10}$ A continuación la revista publica, con un gran rostro, la opinión del cirujano que hizo el primer trasplante de cara en España (loc. cit.: 25). Éste añade que la medicina entiende a los trasplantados como "pacientes de por vida"; e incide en la necesidad de garantizar el anonimato como intimidad. En la primera, es necesario entender que en el caso de las mujeres no sólo se les somete en tanto enfermas, sino que su género es un estado crónico de dependencia médica (y cosmética); además, son objeto de reconstrucción tecnológica (quirúrgica). Todo ello conduce al proceso intrínseco de en-generización (Balsamo, 1996).

${ }^{11}$ Recordemos La fotografía judicial (1890), la Identificación antropométrica (1893), y La antropología métrica (1909) de A. Bertillón. Para España Puig-Samper y Galera (1983). El uso de la cirugía estética por el hampa fue una amenaza para las técnicas identificativas de Bertillón (Martínez-Pereda, 1997: 173).

${ }^{12}$ Haiken (1997) avisa de que el origen del uso social de la cirugía estética, en los años veinte y treinta, estuvo ligada a la promoción laboral. John Staige Davis ya había declarado en 1926: "...si una nueva nariz ha permitido que un veterano de guerra pueda tener un trabajo y casarse, ¿por qué no podría mejorar las oportunidades laborales de un civil o mejorar las perspectivas matrimoniales y por ende, financieras de una mujer?... ¿No era antidemocrático negar a una persona el derecho a mejorarse?". Braudrillard (1974) ha recordado el condicionamiento represivo-sexual de las prácticas estéticas doblegadas por el consumo capitalista. Jay (2007: 114-115) sugiere la taylorización (ahora estética) de los cuerpos.

${ }^{13}$ Esteban (2004: III, 1) defiende este aprendizaje de técnicas corporales y remodelado de volúmenes y formas siguiendo la observación de Wacquant (1995) sobre los boxeadores, que con su entrenamiento específico reorganizan su campo corporal con posturas, rutinas, movimientos, estados subjetivos, emocionales y cognitivos "haciendo resaltar ciertos órganos y capacidades y haciendo retroceder otros". Soley-Beltrán (2012) insiste en las estrategias de resistencia de las modelos frente a los embates publicitarios.
} 
lucha de emancipación laica que busca hacer desaparecer defectos físicos impuestos por el pecado o fomentar la simulación de clase, pero también su "superación". De aquí el afán post-racista de la cirugía estética. Existen primeramente opciones antequirúrgicas o que intentan modificaciones leves sin cirugía, mediante la modelización del cuerpo y sus apéndices: corpiños, brackets y cirugía odontológica, correctores de nariz, y antes tocados, guías y tutores calipédicos ${ }^{14}$.

\section{La nariz mestiza y el balance facial: Tras-loco-corporizaciones de la identidad victimada}

La estirpe racista de la cirugía plástica, sobre todo en la determinación de la proporcionalidad de la cara y su canon, descansa en su naturaleza antropométrica; ésta, correlativamente, en la antropológica (que proporciona un cuerpo filosófico ausente), y ambas en la teoría evolucionista historicocultural, que sumada al darwinismo, devuelve la medicina a su fuente biológico-cultural en un retorno circular. Wen (1921; citado en McCarthy y Wood-Smith, 1992: 908) había seguido la ontogenia y filogenia del cartílago nasal en primates y humanos, encontrando diferencias estructurales en blancos y negros. Pronto emprenderá la cirugía nasal ${ }^{15}$ un traslado desde lo reconstructivo a la corrección de la "anormalidad étnica": Roe, en 1887, si bien proponía las intervenciones quirúrgicas como alivio de las desfiguraciones que podían acarrear además padecimientos mentales, comprende la dimensión social del paciente "objeto de aversión en los otros" (ib.: 894); una vez aceptada la razón que justifica la intervención, es lícito en Roe ocuparse de las relaciones simétricas de la cara, "para poder alcanzar el ideal desde el punto de vista artístico" (íd.). El salto está dado hacia lo plástico como conclusión natural del liberalismo, que encuentra su referente filial estético en el canon histórico de belleza neoclásica ${ }^{16}$. La cirugía ha intentado reificar porcentualmente la belleza, haciéndola descansar en mediciones y promedios antropométricos extraculturales en la garantía científica (balance estético), buscando una objetividad fisio-psico-social que en realidad sólo puede descansar en una estandarización biométrica que hurte el régimen escópico al que la medicina somete a sus pacientes-clientes. La mirada médica es suprainterventora (hiperescópica): "prepara" los objetos para ser mirados. Ramírez (2007) asevera que la belleza no está en los ojos (socioculturales) del que mira, sino en una suerte de gusto universal puramente perceptivo, ligado a la atracción sexual. Se ha postulado desde las ciencias psicológicas el promedio facial en fotografías compuestas para evaluar el atractivo (Langlois y Roggman, 1990; Perrett et al., 1994; Rhodes et al., 1998; Thornhill y Gangestgad, 1999; Langlois et al., 2000, Johnston et al., 2003; Baudouin y Tiberghien, 2004). Asumir estas posiciones supone afirmar la desigualdad racial haciendo descansar en una suerte de fisio-psico-sociología de la belleza, naturalizada en la percepción humana (refinada asimismo en el desarrollo evolutivo), lo que recuerda inmediatamente a la sociobiología. Sorprendentemente, se dan como buenos resultados basados en la fisiognómica, pseudociencia contra la que ya advirtiera Caro Baroja $(1995)^{17}$. Es más, se ha afirmado que podría predecir aspectos biológicos selectivos, como la calidad seminal. Gutierrez de Aguas et al. (2005) muestran estampas de hombres (caucásicos incluso en un grupo colombiano) a un grupo estadístico de mujeres para que los seleccionaran por su "atractivo". El estudio dice correlacionar estas selecciones y la calidad seminal de los individuos mostrados en las fotografías. Las mismas fueron mostradas también a grupos de hombres, que reconocieron como "competidores"a los individuos fotográficos. La comparación

\footnotetext{
${ }^{14}$ Sorprende que incluso juristas entendidos en la responsabilidad de las prácticas quirúrgicas acudan al relativismo cultural en la explicación histórica de las alteraciones corporales, mencionando sólo los tatuajes carcelarios y de criminales citando a Lombroso al referirse a occidente (es decir, lo marginal), poniendo fuera de la historia a la ciencia médica acumulativa, como instancia extra-cultural (Martínez-Pereda, 1997: 108 ss.).

${ }^{15}$ La "nariz étnica" será un tema tratado por la cirugía muy pronto (Rees, 1969; Falces et al., 1970; Flowers, 1977; Ortiz Monasterio y Olmedo, 1977; Matory y Falces, 1986; Daniel, 1992; Romo y Abraham, 2003). Los alcances de la etnocirugía, en Muñiz (2010).

${ }^{16}$ Vecter y Hage (1997) y Farkas y Kolar (1987) repasan los referentes canónicos de la "estética" antropométrica, si bien aparece ésta como conclusión objetiva: es decir, como referente final de proporción cuasimatemática. Rangel y Rodríguez (1999: 190) reconocen a Boticelli, Da Vinchi y Michelangelo, y antes a la tradición grecoromana, que fijaron las proporciones de la cara y del canon de belleza. Odontólogos y cirujanos han validado cánones del arte neoclásico (Farkas et al., 1985 a y b; Ricketts, 1982).

${ }^{17}$ El "atractivo" estaría fundado en la supuesta unidad perceptiva, acordada por consenso estadístico. Empero esta "belleza promedial" no es otra cosa que un producto cultural, un artefacto de laboratorio donde las agregaciones de caracteres fotográficos son "visuales" (Langlois y Roggman, 1990).
} 
sociodarwiniana asegura que el sentido de la belleza parte de "referencias subliminales de las formas y proporciones anatómicas, posiblemente debido a la existencia de una relación entre el atractivo facial y el estado de salud de los individuos" (loc. cit.: 320). Las diferentes culturas estarían usando el atractivo facial como indicador para la inferencia caracteriológica en la elección de una pareja fecunda. Los mecanismos biológicos implicados serían adaptaciones evolutivas "al servicio del proceso de selección de pareja, con el fin de incrementar la propagación de los genes" (íd.). En otro lugar (Gutiérrez de Aguas, 2004: caps. V y VI) se concluye que el atractivo facial es un referente extra-racial y extracultural ${ }^{18}$ (un criterio científico, promedial, supuestamente post-racial pero fundamentado en las posibilidades sociobio-raciológicas).

Lo cultural, ciertamente, estorba a estas tesis como causa, y se quiere como efecto o, menos, contexto modulador. Estas estrategias psicoantropométricas eliminan o esconden lo cultural (el peinado en las fotografías: el enmarcado de las caras de los hombres mostrados en las fichas pretendía minimizar el atractivo sugerido por el peinado, un marcador cultural), pero no "lo físico": lo caucásico, lo racial, y otras marcas o señales faciales (buena salud). Como si "el físico" de la cara no fuera la máscara de Dinoire; o la "buena salud" una forma de virilidad nacional ${ }^{19}$. El criterio parece más raciológico que cultural ${ }^{20}$. Además, la crítica debe llamar la atención sobre que sea la mujer el observador-evaluador de la imagen de los hombres, midiendo la variación de preferencia sexual incluso cuando menstrúan (Gutiérrez del Agua, 2004: $\S 1$. 2. 3.). No se mide la evaluación preferencial sexual mujer-mujer, por ejemplo (cuando se hace hombrehombre es para señalar a los posibles competidores) ${ }^{21}$. Dado que se hace hincapié en la sociobiología de la reproducción sexual ("las hembras como factor limitante de la reproducción", íd.: 83), no se tiene en cuenta la reproducción en parejas homosexuales y nuevas familias (Saletti Cuesta, 2008; Imaz, 2006). Además, se incorporan "índices de masculinidad": "sumatorio de la longitud de la región media-inferior de la cara y la proporción entre la anchura de la cara a nivel de los pómulos por la anchura a nivel de la boca" (íd.: 98). Como señalamos, la elaboración de los perfiles fotográficos son un artefacto cultural y no otra cosa. Todas estas apreciaciones sociobiológicas, como es obvio, tienen consecuencias para la cirugía. Thornhill lo afirma sin tapujos: "[l]a industria de la belleza... es el resultado de nuestras preferencias estéticas. Las modelos... son bellas de acuerdo con nuestros patrones psicológicos de belleza. La cirugía plástica es consecuencia del deseo de la gente de corregir sus asimetrías y resaltar sus marcadores hormonales" (en Desfilis y Font, 2001: s. p.) $)^{22}$.

Aunque estas cuestiones no incumben directamente a la cirugía estética, algunos autores reconocen que la medición de la cara atractiva arroja grandes variaciones, de lo que se desprende que la superación racial por vía quirúrgica atentaría no sólo contra la diversidad humana (aunque ésta pueda expresarse a veces en el individualismo liberal), sino contra la identidad nacional, acarreando consecuencias nefastas que el cirujano no puede asumir: "Si los valores promedio pertenecientes a la cara atractiva fueran correctos -expresa Ohmori, 1992: 1516-, la cirugía estética sólo estaría dedicada a producir un gran número de caras parecidas, lo que podría significar la pérdida de la individualidad de las personas $^{23}$ y constituiría en sí un defecto fundamental". La crítica de este autor sobre la arfetactualidad de

\footnotetext{
${ }^{18}$ También habla del género (post-género entonces), pero no lo asume metodológicamente.

${ }^{19}$ La propia clínica informa de síntomas silenciosos; tez y piel, expresión, afeitados, miradas de dominación y sumisión escaparían en buena parte a "la salud"; amén de moldeaciones de cirugía estética.

${ }^{20}$ El mismo autor (íd.: 99), siguiendo a Magro (1999), indica que: "Por añadidura, se ha planteado que los hombres y mujeres de diversas edades, razas, culturas y regiones geográficas muestran un gran acuerdo en la valoración de la belleza de la forma humana con una preferencia por las características o proporciones anatómicas que son intermedias o más derivadas, sintiendo aversión por los rasgos más primitivos o menos evolucionados. Esto podría indicar que nuestro sentido innato sobre la estética y la belleza de la forma humana está basado en referencias subliminales hacia las formas y proporciones anatómicas derivadas que son exhibidas por los humanos modernos". Una estética darwiniana (Thornhill, 1998).

${ }^{21}$ Cuando las mujeres evaluadoras están menstruando escogerían preferentemente a hombres con rasgos ligeramente afeminados en reconstrucciones fotográficas que mezclan rasgos masculinos y femeninos: una exageración de los rasgos masculinos denotan atributos negativos de personalidad o bien hacen aumentar la edad estimada (loc. cit.: 11).

22 La crítica antropológica a la sociobiología es conocida (Caplan, 1978; Shalins, 1982; Lévi-Strauss, 1985 y 1993 ; Schiebinger, 1987 y 1993; Bleier, 1988; Pérez y Currais, 1991; Lewontin y Kamin, 1996; Harris, 2000).

${ }^{23}$ Una consecuencia parecida a la pérdida de la variabilidad autóctona de biodiversidad en los procedimientos de ingeniería biológica de la industria alimentaria, fundamento más nacional que bioconservador.
} 
la medición antropométrica y sus sesgos culturales ${ }^{24}$ es demoledora para el caso de Japón. Los estándares numéricos del "índice de belleza" para los ojos y la nariz niponas presentan sesgos: el marco craneofacial no fue evaluado con técnicas cefalométricas, sino conforme al modelo de una popular actriz. Los datos con los que se obtiene la "cara promedio" fueron conseguidos en una muestra con deformaciones de nariz y marco facial (op. cit.: 1516-1517).

Porque, en definitiva, la medicina no es capaz de establecer un criterio extracultural y ahistórico. Es decir, la cirugía (el modelo quirúrgico de belleza promedial) se propone como canon mismo de belleza (belleza quirúrgica), y su espejo supuestamente anatómico es, en una ficción artefactual, la belleza de una modelo famosa y, por debajo, una aparatosa deformidad: es decir, el referente último es siempre "el propio marco" sociocultural, su "contexto", la "invariable moduladora", su "efecto", el deseo del hombre en la posesión del fetichismo anatómico ${ }^{25}$. Con esto, la cirugía estaría fijando o sancionando una belleza normativa y procedimental ya de por sí promocionada (por los intereses del consumismo contextual), asimilando el nacionalismo sublimante de la raza con el ideal liberal.

El afán post-racial de la cirugía estaba ya en su desarrollo histórico y conceptual y vuelve a redundar en la raza como un lastre que el evolucionismo biológico no parece que pudiera superar con una ética liberal; es así que resurge el evolucionismo histórico-cultural, antes que biológico ${ }^{26}$. El liberalismo se pondría ahora en la posibilidad o no de comprar la operación estética manteniendo una individualidad aparente y escenificada en la lozanía perpetua que confiere la mirada dominante: la superación racial se mercantiliza en un fondo de miramiento ético y ascensión social que, de todas formas, no puede superar el racismo al necesitar proponer un canon referencial que no deja de ser el caucásico y exitoso. Lo no bello, o lo menos bello en la escala evolutiva era considerado una anormalidad prescindible ${ }^{27}$, que puede ser superada aceleradamente por la medicina eugenésica inmediata sin esperar a la resolución superadaptativa de la evolución natural de "las razas" (que abriría más la diversidad sobre la que trabajaría la diferencia social). Preminger (2001), a propósito de la nariz judía (cfr. Gilman, 2001: 88 ss.), recuerda su clasificación como anormalidad racial. La nariz negra tendrá asimismo un tratamiento quirúrgico con un mismo interés asimilativo (Rees, 1969). McCarthy y Wood-Simith (1991: 985), en fin, explican la motivación por la rinoplastia en la sociedad multiétnica estadounidense como deseo de asimilación ${ }^{28}$. El factor de éxito social por el blanqueamiento deja al cuerpo como instrumento que traslada y mejora la identidad (o que la promociona disimulándola), sin resolver la cuestión de fondo de la desigualdad social, que queda aparcada como moralidad retrógrada. Las variaciones étnicas (en verdad, raciales), se van a conformar clasificatoriamente, con arreglo al alejamiento antropométrico respecto del modelo caucásico (asimismo estandarizado). McCarthy y Wood-Smith (1991: 908-911) establecen esta prelación categorial: del perfil nórdico al mediterráneo, dejando al margen al oriental y negroide. Por otra parte, la dimensión meramente estética de esta cirugía, la vocación instrumental del cuerpo y las posibilidades de transterrar (translocalizar y tras-corporalizar) la identidad, han llevado a establecer prácticas modeladoras más allá de las simplemente correctoras de la anormalidad. La raza que coincide con la nación se adorna (una redundancia); la que no, se corrige. Ohmori (1992: 1515) explica: "En Oriente, la cirugía estética de los ojos y la nariz... [añade a la] cara normal una belleza adicional [como cosmética]; mientras que en el pensamiento occidental las deformaciones deben ser corregidas para alcanzar una más completa identidad". Los cambios mundiales llevan a este autor a predecir un traslado del interés estético oriental

\footnotetext{
${ }^{24}$ Hay que tener en cuenta que si la belleza quirúrgica es una ficción antropométrico-médica, las "razas/etnias" lo son asimismo (Schwartz, 2001; Afshari y Bhopal, 2002; González, 2003; Vanegas et al., 2008), incluso de la misma índole antropométrico-médica y, en definitiva, antropológica. La superación de las razas por el mismo medio racista de la cirugía respondería al refinamiento de lo mismo: a un simple traslado ideológico de lo racial a lo social. Lo mismo puede decirse del género.

25 Resulta paradójico que algunos cirujanos adviertan a sus clientes que no deben desear modelos estéticos cinematográficos, dado que la cirugía estética debe estar basada en "realidades objetivas" (e. gr., Canto et al., 2006: 24).

${ }^{26}$ Artistas como Sterlac han abogado por la superación del evolucionismo en la obsolescencia del cuerpo.

27 Las "desproporciones" son calificadas como cuasi- patológicas: hipoplasias nasomaxilares y simples gibas nasales, excesos verticales del maxilar, microgenias (McCarthy y Wood-Smith, 1991: 907-908).

${ }^{28}$ MacGregor (1967) ya había certificado los impulsos disimuladores de los rasgos étnicos en pacientes quirúrgicos. McCarthy y Wood-Smith (íd.: 893) recuerdan la fisiognómica mencionando que la rinoplastia es la consecuencia del sufrimiento social: nariz grande=personalidad siniestra; nariz pequeña=debilidad; nariz desviada=personalidad criminal; nariz roja y grande=alcoholismo. Raymond Passot legitimaba la "corrección de la fealdad" para prevenir el suicidio y las neurosis.
} 
hacia la postura correctiva occidental, así como a la copia del modelo canónico o "belleza transnacional". Sin embargo, la identidad conservadora del modelo corrector occidental se ha superado en la mejora de la identidad personal, aunque Ohmori se queja de la estandarización del canon, y en oriente ha dado identidades nuevas, "bellezas quirúrgicas": fenómenos como el seikei bijin, de apariencia "poco natural", con características femeninas o masculinas difuminadas, lo que abre a otras posibilidades identitarias y de identidad sexual cruzada ${ }^{29}$.

En nuestro contexto, y de un modo más detallado, nos interesa trazar estos tópicos en la denominada "nariz mestiza" (Ortiz Monasterio, 1977 y 1986; Ortiz Monasterio y Olmedo, 1977). Sus características se establecen por comparación jerárquica: se considera que tiene una piel intermedia entre la negra y la blanca, con una forma peor definida y difícil de trabajar (Rangel y Rodríguez, 1999; Duarte y Sánchez et al., 2005); dando un "efecto visual más que real cuando se compara con los estándares estéticos aceptados y con el resto de la cara" (Rangel y Rodríguez, 1999: 189). Nótese esta contundente "realidad", o cómo el artificio antropométrico del balance estético objetiva desequilibrios como realidades (lo que llama a la anormalidad y a la corrección). Esto muestra que, por defecto, "prácticamente todas las narices mestizas tienen proyección inadecuada de la punta nasal (ptosis)" y necesiten "sobrecorrección" (Rangel y Rodríguez, 1999: 196) con arreglo al "canon estético indoeuropeo" (Duarte y Sánchez et al., 2005: 94), buscando la intervención estética "ideales naturales congruentes" con el resto de la cara (Gálvez Chávez y Millán, 2007). El entronque antropológico, que funciona como aparato científico de base clasificatoria y como excusa ideológica, es manifiesto en autores que siguen a Ortiz Monasterio, como Duarte y Sánchez et al. (2005) o Rangel y Rodríguez (1999) ${ }^{30}$, cuyo texto recoge el origen de estas concepciones: etimología del término mestizo, clasificación diferencialista, origen histórico y referencias naturalísticas y antropológicas; lo que da lugar a clasificaciones nasales, dando paso a la nariz mixta (rango desde la subplatirrina a la paraleptorrina, intermedia entre la nariz negra y la caucásica). Este modelo no sólo ignora las variaciones fenotípicas de los nativos y los colonizadores (y su mismo tronco que aleja y acerca), sino que asume un discurso raciológico como ratificación historiográfica de la separación de razas (sin tener en cuenta además que el referente caucásico prosigue la asimetría colonial racista); y de la que desprenden consecuencias clasificatorias faciales y nasales, útiles para la cirugía. Acto seguido, recuerda los orígenes de la medición antropométrica facial: en efecto, Topinard (Paul Topinard, 1989; Arquiola, 1978) ofreció mediciones de la nariz en 1890 que servirían como antecedente para la biometría actual aplicada a la cirugía reconstructiva y estética.

Una mayor cantidad de rinoplastias, por otro lado, son primarias (nariz mestiza y negroide, rinodeformidad o laterorrinia) o, en el caso de las secundarias, postquirúrgicas (e. gr., Gálvez, 2005); lo que lleva a asumir un gran porcentaje de intervenciones estéticas en población mestiza. La cirugía, aparentemente, no es sólo preferencia femenina, si bien la liberación de la mujer y su mayor poder adquisitivo han producido fenómenos de consumo encarnado. Una cuestión adyacente es que una vez diseñada la nueva nariz (caucásica, pequeña y respingona -el orgullo parece aquí aristocrático-) e intervenida la nariz mestiza o negroide, puede resultar incongruente con el resto de la cara mestiza o del cuerpo, por lo que se requieren nuevas y sucesivas intervenciones para lograr un balance facial quirúrgico. Un desajuste que no obstante se atribuye a las características inadecuadas de la nariz, el cráneo/mandíbula o la piel no caucásica de estos promocionados (Gálvez Chávez y Millán, 2007). Más adelante, los cirujanos que intervienen en población mestiza, asiática o negra, propondrán estandarizaciones estadísticas para definir perfiles racio-nacionalistas (Gálvez Chávez, 2005; Gálvez Chávez y Millán, 2007).

\section{El vaso expositivo de la centralidad escópica}

Superando la falacia estadística, podemos aseverar que el canon estético se hace físico además por su figuración normativa que, merced a la omnipresencia mediática, sitúa y propone a los sujetos (cuerpos subjetivados) como objetos (cuerpos objetivados) de mira en la centralidad escópica. Los individuos quedan sujetos en su producción (que con los medios de reproducción y presentación fotográfica pasan de ser complementarios a ser centrales) de un alter ego mecánico e irrefutable, autopresentado-mirado,

\footnotetext{
${ }^{29}$ Los "femio-kun" japoneses juegan a esconder sus atribuidos rasgos sexuales en las ropas, atavíos y formas que ofrece la industria de la moda, procurándose ambigüedades efectivas (Nieto, 1998: 33).

${ }^{30}$ La base antropométrica de estos modelos en Laurence et al. (1996).
} 
sometido al hueco expositivo, la bañera de disección, bandeja de portaobjetos, fondo y tarjeta estereoscópica de una mirilla Holmes (con Tagg y McCauley, en Jay, 2007: 113) ${ }^{31}$. Existen accesos normativizados a este fondo del vaso expositivo que da paso franco a la elaboración de las subjetividades; y la resistencia pasa precisamente por posicionarse anormativamente en la centralidad del visor. Las imágenes tópicas sobre raza y sexo estarían significando retóricas normativas que legitiman los accesos a los (determinados) cuerpos. La necesidad clasista y neocolonial requiere de un racismo sostenido que se hace complejo.

Nip/Tuck ("A golpe de bisturí"), una serie televisiva norteamericana de indudable éxito es un drama médico ambientado en el mundo de la cirugía estética: anunciado como "morboso e inquietante", ambientado en una Miami excéntrica y lujosa, y protagonizado por dos cirujanos guapos y exitosos: uno, judío, con un fracaso familiar que intenta enmendar; el otro de origen cubano, soltero frívolo, millonario vanidoso. La serie asimila modelos liberales de éxito y belleza, con una vida de lujo ${ }^{32}$; el mundo de la jet set y el hampa rosa (tradicionalmente vinculado con la cirugía para procurarse anonimato y réplica) son sus clientes; como algunas clientas imposibles, de fealdad irrecuperable, cuyo afán promocional se tacha como extravagancia de las aspirantes, acaso con problemas psíquicos; pero cuya persistencia devela el vaso en el que inscribirse. Parece aún que la opción liberal de esculpirse bien frenada por la cuna, ahora camuflada en la estirpe de un buen cuerpo, una buena masa. En el episodio "Abby Mays" ( $3^{\circ}$ temporada) encontramos un modelo para comprender por qué el cirujano comienza su entrevista interiorizando el gusto estético en la paciente/cliente: "-Dígame, ¿qué es lo que no le gusta de ud.?" La cual responde asumiendo el gusto/culpa, al calificarse como "monstruo" o "bolsa", o presentándose como fea. "-Sólo quiero ser bella, para ser amada por alguien como ud., [aunque sea] inalcanzable". La conversación gira entonces sobre la opción de buscar un novio feo, "generalmente los mejores amantes", a lo que la clienta reclama estar en el mundo (informada por la coacción de los modelos mediáticos) y necesitar la cirugía como forma promocional. Insiste exponiéndose más, hasta que el cirujano, pidiéndole el pintalabios, la hace desnudar para marcar de rojo las zonas que recomienda operar: "-Tu primer paso hacia la belleza es echar un gran y frío vistazo a la realidad". Confundiéndola un momento con su antigua amante, excitándose, vuelve sobre la realidad corporal de la cliente: "-La belleza es simetría, y tú no tienes nada". Cuando se gasta el pintalabios la muestra ante el espejo, toda marcada de trazos rojos. Declara su cara, además, como causa perdida. "-Pero si esculpo tu cuerpo con liposucción puede ser salvable.... Posible, cortable, lista para ser reescrita". Si el lema general de la serie ( $2^{a}$ temporada) es "Dígame qué es lo que no le gusta de usted", primera pregunta que los cirujanos hacen a sus clientas, la respuesta de "Abby Mays" expresa, entrando en el juego irónico del cirujano vanidoso, que quiere ser hermosa para que la amen hombres como él (cirujano, rico, guapo y exitoso: "lo que toda mujer anhela"), aunque lo considere inalcanzable; en su defecto, aspira a solteros bien cotizados. Una metáfora final, estar o entrar en el "mercado", es ya asumidamente mercantilista del valor estético y social, y la dificultad de la competencia sexual. La historia, que continúa con alusiones tópicas ("los feos son los mejores amantes porque compensan las carencias"), pone a la protagonista del cambio estético en una tesitura metaficional: "Veo la prensa y la televisión y estoy (por ellas) influenciada (sobre los cánones de belleza y las llamadas al cambio)". El cirujano entra "sádicamente" en la recriminación social, recordándole como realidad el exceso de cuerpo, y el sacrificio. Toma el pintalabios, símbolo fetiche de la feminidad, y le marca con segunda violencia las partes del cuerpo que deben someterse a cirugía (una escritura corporal que exhibe un cuerpo extenso y social). El canon se hace físico a partir de la producción del ensueño cuando el cirujano ve en esta persona a su amante anterior, rubia y esbelta ( $y$, no por casualidad, actriz y directora de cine porno) en la excitación del marcado del cuerpo de la clienta: cuerpo que queda completamente marcado (listo para ser reescrito, dirá) con círculos y líneas rojas que recuerdan la sangre martirial. Sin embargo, el pintalabios se agota, no es suficiente, manifestando la imposibilidad de la "cuna" o "clase" morfogenética, de la que se carece: "La belleza es simetría, y tú no la tienes", dirá el cirujano. La remoción corporal simbólica no resuelve el anhelo

\footnotetext{
${ }^{31}$ Martínez Lirola (2010) califica la representación femenina en la publicidad de clínicas estéticas como "violencia de género visual".

${ }^{32}$ En un anuncio sobre la inauguración de una clínica privada de cirugía plástica y estética en España hemos podido comprobar la implantación no tan ficticia de estos modelos: incluyendo fotografías de la pareja médica (cirujanos estético y plástico), guapos, bien vestidos, exitosos (de gran currículo), en pose asertiva; y subrayando que el modelo que ofrece su clínica (instalada con moderna tecnología en una planta de un hotel fuera de la ciudad, dotado con balneario y todas las comodidades para un trato íntimo) es importado de los EE. UU. (DN, 18-3-2009).
} 
de ser deseada por el cirujano, porque "[l]a cara es caso perdido". Debería cambiarse todo o incluso no haber nacido. Se ha heredado la distinción biológica o se es plebeyo. Pero éste último es aún explotable como esclavo: "[E]l cuerpo es [así marcado] follable" ${ }^{33}$. Esta "reescritura" cultural del cuerpo lleva del pintalabios que escribe sobre el mismo al bisturí. Pintalabios/bisturí/falo en las manos del cirujano que cede poder fecundando-emancipando.

La cuestión del racismo médico de fondo sube a la superficie con un sentido macro en el capítulo "Madison Berg" ( $3^{a}$ temporada). La paciente llega a la consulta con su madre, y ésta expresa su condición judía cuando recuerda que en su juventud se recomendaba operarse la nariz para encontrar marido. Lo hizo cuando la hija reconoce que si no hubiera sido así ella no hubiera nacido. Hoy no tiene como prioridad encontrar un marido y casarse, sino una expectativa estética y celebrativa (los dieciséis años) ${ }^{34}$. Los cirujanos informan de operaciones en narices judías, tendiendo hacia perfiles más "refinados", y les enseñan un book de narices judías operadas. Es en él donde la paciente reconoce a una compañera de clase como judía. Entiende que su compañera de clase había disfrazado u ocultado su condición y la paciente acepta entonces ser intervenida, pidiendo la nariz de su amiga. Tras ser operada regresa a la escuela con la nariz protegida con protector. El capítulo continúa con otro sentido. Porque allí es señalada como "trabajito" (es decir, una judía operada) precisamente por la amiga/novia skinhead del hijo de uno de los cirujanos. Éste cuenta que esa chica sale del "matadero" de su padre cirujano, y su amiga lo convence para recriminarle esas prácticas. Ésta verbaliza expresiones cínicamente racistas: "Judíos con grandes narices y grandes nombres. Completamente patético. La venda en su cara no está cubriendo su nariz, está transmitiendo su odio a sí misma". El discurso moral arremete contra la convención social del "quiero ser" y la homogeneidad física. Su novio reconoce que él no es así (quizá una gentilización); su situación problemática lo convierte en "invisible" para los demás. La novia, además, le pide entrevistarse con el padre, el cirujano, porque está escribiendo un trabajo escolar sobre "Los imaginarios en la cultura popular". La entrevista tiene lugar con ambos cirujanos y el saludo de cortesía versa sobre la adivinación, por parte de la novia, de los ascendientes raciales de ellos (orígenes caribeños de uno de ellos, con nariz ancha, etc.). Cuando le preguntan en qué pueden ayudarla, ella les pide: "Quiero que hagan mi piel negra. Básicamente, quiero verme afroamericana". Ni que decir tiene que la chica es rubia y blanca. Los cirujanos le responden que ellos no oscurecen la piel. Y ella, cínicamente, asegura que sí la "aclaran". Les pide que ajusten el hecho moral de convertir a las personas de un color en otro. Sale a relucir Michael Jackson, "más blanco que yo", caso que no es aceptado por los cirujanos. Ella menciona, más cercano, los casos, que sí operan, de narices judías. Les recrimina el porcentaje de ingresos que vienen directamente "de sus dedos", y ahora el modelo es sustituido, trasladado del canon racial al estético: de nombrar a Michael Jackson (los cirujanos no consistieron ser llamados racistas), al de Heidi Klum o Kristen Dunst, "distinguidamente anglosajonas y chicas gentiles", modelos a los que las niñas judías operadas quieren parecerse. Los cirujanos, como es obvio, no admiten este traslado de sentido (el del racismo estético). El punto de vista de la chica es que ellos están "realzando características físicas que imitan los modelos de nuestra cultura": "En resumen, todo lo que hacen es la adoración a un arquetipo. Se trata de hacer a todos blancos y arios. Eso no es correcto". El cirujano judío intenta defenderse, puesto que "ofrecen una opción" sin "preferencias" estético-modélicas concretas, justificando la escapatoria del racismo instalado en la sociedad. El colega cubano impide que siga y le pide que no se justifique. El guión prosigue, situando a la skinhead en una posición plenamente nacional-racista: "[Yo creo que sí tienen que explicarse.] Poco a poco, ustedes y otros cirujanos plásticos están creando una nación de blancos 'no blancos'". Esta argucia del guión nos habla, a nuestro entender, de la democratización (aunque esté atravesada por su acceso dinerario, es decir, social) de la estética y la cirugía, haciéndolas una opción igualadora y superadora de las diferencias raciales (un posthumanismo ambiguo y degenerado para la posición racista). En la apariencia estética se difuminan las diferencias socio-raciales, lo que proporciona a la estética médica una coartada liberal. Casi una eugenesia estética y sociomédica curiosamente criticada desde posiciones nacional-racistas: "A largo plazo están eliminando las razas [por medio de casamientos y parentelas mixtas]", dirá más tarde. La skinhead ve una competencia por la técnica, que debería ser patrimonio blanco, concluyendo con una aseveración tremenda: "Cada vez que hacen liposucción sobre un gran culo negro, o liman el hueso de una nariz judía, hacen a esa persona más viable en el mundo". El post-racismo médico es visto aquí como un atentado a la distribución natural de los dones físicos o incluso a la provisión divina. La conjura judía para el control del mundo aparece

\footnotetext{
33 Una categoría clasificatoria usada por ambos cirujanos para referirse a las mujeres que conocen.

${ }^{34}$ La coreana Before and After: Plastic Surgery Clinic (2008) sí relaciona cirugía y matrimonio (cap. 7).
} 
inevitablemente, ligada también al liberalismo: "¿Ese es su plan maestro o es el resultado de lo que ustedes hacen para vivir?". Los cirujanos la echan sin contemplaciones y la llaman Freak, advirtiendo a su hijo que su novia es una racista ${ }^{35}$. Pero el chico se acuesta con ella descubriendo sus esvásticas tatuadas, lo que sugiere el marcaje "blanco" del "cuerpo legítimo". Ella niega pertenecer a una secta neonazi y dice estar en contra de que la gente se avergüence de lo que es y pierda su identidad, volviéndose irreconocibles. La homofobia tampoco se hace esperar. Finalmente, reconoce que no es una nazi, sino "una purista". Una purista que su novio ve como hermosa, dejando marcar su cuerpo converso o renegado con un piercing de motivos nazis. Después visitan a la familia de la chica y descubren sus aficiones (coleccionan figuritas de negras gordas, etc., que fijan el exotismo anecdótico del "como eran antes de querer ser como nosotros", con alusiones a la virilidad negra). El chico es aceptado por el padre de su novia porque se había peleado en el pasado con un transexual, manifestando hombría. Al averiguar que el padre del chico es cirujano, le dice: "¿Así que creciste con ese discurso liberal, multicultural, polisexual...; y aún así te convertiste en un hombre de honor, eh?". El refinamiento estético debería ser exclusivamente blanco, porque de lo contrario sirve a la igualación socio-racial. La argucia permite la aceptación del status quo de la sociedad contemporánea, post-racial por la democrátización liberal, al encasillar la crítica en el discurso racista, sobre el que trabaja. No duda del sistema social de base profundamente racista y desigual, algo más que un discurso extremo desplazado, superado y hasta combatido, y el éxito pasa por la apariencia estética de acercamiento o mímesis con el canon triunfante, que de alguna manera asimila por la carne un origen minusvalorado igualmente. Triunfa así el cuerpo sangrante, post-físico, que disimula la marca étnica reificándola en la exhibición quirúrgica. Y sitúa a la técnica (médico-quirúrgica) como extra-cultural, económica. La crítica no puede aceptar la aberrante posición raciológica, desde luego; pero el equilibrio democrático de la cirugía liberal puede obviar también la condición neo- o post-humana (Halberstam y Livingston, 1995), cuyo horizonte desconocemos. Ambas posturas quedan abolidas en la serie en favor del liberalismo: la primera negada con razón, la segunda hurtada; sin considerar que de la primera se nutre y en la segunda deviene. La raciología no merece objeciones para rechazarla de plano y combatirla definitivamente. Pero de la segunda, que aparece como cuasi-igual a la primera en la estrategia del guionista (equidistante), sí podríamos argumentar en su favor. En la identidad autodirigida de la contemporaneidad, la antropología de base habría dejado paso a una maquinología libidinal, hipertélica, del cyborg deseante. Que quizá haga más complejo el racismo, y que atenta contra el concepto de Humanidad. Porque la segunda historia de esta serie ("Rachel Ben Natan"), que tiene que ver con ese mismo hijo descarriado de uno de los cirujanos, que entra en el hospital de quemados tras un accidente para rehabilitación, añade aspectos ficticios en los que había caído la trasplantada Dinoire. Allí conoce el personaje a su rehabilitadora, Ben Natan, quemada y deformada como víctima de la explosión de una bomba portada por un suicida palestino en Israel. La fe en mantener su rostro como está (superioridad en constante lección moral, de supervivencia y superación sobre un mundo lesivo) se tambalea en la rehabilitadora cuando se descubre en su cara un diente incrustado por la explosión, atribuido al terrorista. A partir de aquí, la entereza de Ben Natan se desploma, que siente la ajenidad de su cuerpo invadido y violado repetidamente por numerosas esquirlas más (metralla corporal de partes del cuerpo del terrorista). Cuando se somete a la operación aparecen los problemas morales de qué hacer con los restos minúsculos del terrorista que la colonizaba: hacen que éste cobre vida y se aparezca como delirio paranoide incluso al cirujano. Finalmente éste, que pretendía arrojarlos a la basura como deshechos corporales, es convencido para que entregue los restos; cosa que hace trasladando la decisión a Ben Natan, que los devuelve a la familia del palestino en una pequeña urna después de muchas dudas. Un hurto del emsamblaje postreducido a estrategia de conciliación democrática.

Como es lógico, la relativa animadversión que suscitan series como estas redundan en beneficio publicitario, y la supuesta provocación que retrata la sociedad (corrupta) actual no deja de ser una pose adentro del sistema que explota el morbo y otros sucedáneos: la vida libre y licenciosa, en un engranaje con la moralidad pública, la figura patriarcal, las fuerzas religiosas ${ }^{36}$. De hecho, algunas campañas

\footnotetext{
${ }^{35}$ Recordemos que el término Freak remite a malformaciones físicas.

${ }^{36}$ El drama japonés Artificial Beauty. Seikei bijin (2002) subraya la dependencia femenina de la estética y la promoción para el matrimonio ventajoso. La coreana Before and After: Plastic Surgery Clinic (2008) comienza, en el trastocamiento de los dibujos tradicionales de Cenicienta, la Bella y la bestia y otros, con el calzamiento del pie pequeño y delicado de una mujer en un zapato de cristal con gran tacón. Esta representación de la transformación principesca se amplía al hombre, que pasa de monstruo plebeyo a bello príncipe. Todo lo cual, además, asegura la felicidad, simbolizada en la
} 
conservadoras que la censuran lo hacen a causa de las obscenidades, homosexualidad, violencia, etc., y no por el contenido de fondo, en un combate por imponer otro velo de intimidad en la mirada escópica. El juego entre lo abyecto y la escenificación de la carnalidad se alimenta de recomendaciones como la del USA Today: "repugnante, absorbente y completamente audaz". Distintos programas televisivos compiten ya no sólo en asuntos menos sangrantes como el control de la obesidad: "Cuestión de peso" u "Operación Bikini", y "The biggest loser" son formatos internacionales que exploran los dramas personales de los participantes (reality) sometidos a control dietético, disciplinas deportivas, coaching, estilismo, pero también a la cirugía, como Extreme Makeover (Quaglio, 2007; Tait, 2007), con supuestos servicios públicos de divulgación sanitaria (hábitos alimenticios, ejercicio). Programas que han disparado la asistencia, sobre todo de mujeres, a las clínicas de adelgazamiento y estética. Un desarrollo estético que, superando las moralidades sociales (matrimoniales), en Japón puede estar creando nuevas formas estéticas e identidades generacionales (Miller, 2004), pero cuya ética en torno al cuerpo revierte en el consumo de representaciones, como la escenificación de la cirugía estética en los manga y anime (Hanabusa, 2008).

\section{La vulva pornográfica}

La cirugía estética que mayoritariamente recae sobre la mujer como objeto estético mantenido y perfeccionado está dirigida por el deseo masculino. Las nuevas tendencias quirúrgicas inciden en el agrandamiento del pene como afirmación dominante y la reducción de la vulva como sumisión virginal adolescente y performance consumativa (Pardo et al., 2006; Goodman, 2009), presumiblemente conforme a cánones de eficacia consumativa y fantasía pornográfica. El rejuvenecimiento de la vulva simularía la de una prepúbere/púbere, bajo la imaginería de la juventud y la virginidad de la nulípara, pero acaso también prevendría contra la homosexualidad femenina en la ficción machista. La necesidad de asexuación de los genitales femeninos es proverbial. Es claro que la intervención en la vagina es antigua por motivos urológicos o ginecológicos, aunque apenas se menciona la extirpación del clítoris u otras partes vaginales en las histerectomías atribuidas a las histerias nosológicas o a cuadros biológicos malignos, y relativas en ocasiones al control del deseo ${ }^{37}$. Díaz Rojo y Morant Marco (2008) relatan las clases de intervención vulvar actual con interés estético: labioplastia; reducción de los labios mayores para evitar que se aprecien con ropa ajustada, tanga o bañador; lipoinfiltración de labios mayores; remodelado púbico con o sin lifting, para corregir el abultamiento del pubis eliminando excendente de grasa; rejuvenecimiento vaginal, para incrementar su tonicidad y mejorar las relaciones sexuales. Los perfiles de las pacientes son jóvenes acomplejadas por el tamaño o forma de su vulva; y mujeres mayores de 47 años, insatisfechas con el aspecto estético en general, y buscando un rejuvenecimiento genital. Además de la culpabilización o la atribución de trastorno psíquico, el referente es mediático y pornográfico para satisfacción de la pareja masculina, ya que las pacientes suelen acudir "al cirujano pidiendo tener una vulva concreta, mientras le muestran una fotografía de revistas eróticas como Playboy o Penthouse" (íd.). En diversos documentales sobre labioplastias puede verse la labor de los disimuladores virtuales que con retoque de imagen recortan los labios mayores de modelos de revista para público masculino. En el reportaje Mujer sin complejos. Prisioneras de la imagen $(2003)^{38}$ se aborda esta cuestión en el marco de la domesticación femenina en el mercado cosmetológico y médico. Comienza con la caracterización estética de la presentadora por medio del peinado, el maquillaje y el photoshop ${ }^{39}$, su preocupación por las arrugas, y una encuesta a fornidos albañiles sobre el límite de edad de las mujeres merecedoras de piropos. El ingenuo pasado de modelo (fracasado por baja estatura y exceso de peso) de la presentadora mostrando fotografías de prensa de esta

boda. El capítulo 7 se titula, precisamente, "Plastic Surgery and Marriage".

${ }^{37}$ Mutilaciones de la vulva fueron aplicadas en Europa, no sólo dentro del contexto de la rigurosa ascética religiosa, sino como medio sanitario para el control de la histeria y la sexualidad (Álvarez Degregori, 2001; Santiso Sanz, 2001); algunas prácticas estéticas occidentales de moldeado corporal están en relación con la satisfacción corporal por medio del aumento del deseo en el otro (Santiso Sanz, 2001; Álvarez Degregori, 2001; González Cortés, 2001).

${ }^{38}$ Dirigido por S. Bergman y producido por Viewpoint/VPRO (La noche temática, TVE2, 1-3-2008).

${ }^{39}$ Más adelante muestra el documental el manejo de esta herramienta de retoque digital en el caso de modelos (estrechamiento de cintura) y playmates (ensanchamiento de pechos), y se aplica en el antes y el después a la periodista. Existen programas informáticos donde a partir de una fotografía personal cualquier usuario puede retocarse y ver los efectos de una posible intervención (al igual que se disponen de programas similares para el cambio de look en peluquería y vestido). 
época la lleva a la necesidad de asumir sus cambios corporales (aceptando la "decadencia natural") ${ }^{40}$. El escrutinio milimétrico de la piel de la cara, la inspección de la arruga, es valorado por el técnico cosmetólogo (un cirujano) con el criterio de la edad cronológica y su correspondencia con "la edad de la piel". La "conversión" de la arruga en "marca permanente" es su diagnóstico. El gesto (sonreír, alzar las cejas, gesticular) delata la arruga/máscara-de-gesto-detenido, que acerca a la condición de madre (no de esposa), lo que muestra la exigida pose estática y dócil, la inmovilidad de lo femenino ${ }^{41}$. La vulgar "normalidad" del envejecimiento "natural" de la piel debe corregirse con la cirugía ${ }^{42}$, porque las mujeres que se someten a cirugía son "personas que quieren seguir siendo normales", no tener una belleza especial. Vejez y enfermedad/decadencia, por ende, son sinónimas, y el argumento se desplaza de la estética a la salud/envejecimiento. La castración de la expresividad se recuerda cuando expertas en cosmetología llaman a las modelos y actrices como excusa para la cirugía: "No hay más que fijarse en cualquier actriz de más de treinta. ¿Sexo en Nueva York? Ninguna puede fruncir el ceño"43.

En todo este contexto, algunas mujeres relatan en el documental la oferta y demanda del rejuvenecimiento de la vulva y labioplastia de los labios menores. El modelo se pone en la centralidad escópica, que opera produciendo diferencias (Hernández, 2006; Córdoba, 2010):

[Las mujeres deberían ser, cuenta una paciente intervenida] como las que salen [énfasis añadido] en el Playboy; [L]a sociedad actual te dice cómo deben ser las mujeres, y si no cumples con esos criterios, si no tienes ese aspecto, eres diferente..., y ya sabes cómo son los hombres, si tienes novio o marido sabes que siempre están ojeando esas revistas babeando con las fotos de actrices; creo que por eso intentamos ser así, para que nos miren de la misma forma (y poder competir con ellas.

Por último, la periodista se deja aconsejar por el cirujano David Matlog ${ }^{44}$, que la mide, toca y señala dónde y qué esculpir, mientras aquélla graba con cámara toda la sesión. El calificativo que se considera como objetivo es "dejar el cuerpo muy sexy". Como una performance tecnomédica de violación. La cámara recoge también la evaluación de Matlog de la vulva de la documentalista. Le aconseja eliminar grasa del muslo y reducir los labios menores de la vulva, así como eliminar finalmente grasa de los labios mayores y del pubis, acabando con una expresión machista como "necesitas esto cielo ${ }^{\text {A5 }}$. Acto seguido el cirujano asimila el rejuvenecimiento de la vulva como requisito para el aumento del placer sexual (vejez=frigidez), hace el presupuesto económico (con cifras astronómicas), y concluye con la referencia al modelo erótico: "Así conseguirás un look digno del Playboy", que "garantiza" quizá más como hombre que como cirujano. Cuando la mujer reclama su belleza original, Netlog deposita la confianza en sí misma (en una suposición de incapacidad manifiesta), e inmediatamente alude a la necesidad de esculpir los brazos, la papada, etc., entre "cielos" condescendientes y agresividad masculina. El derrumbe de la autoestima de la periodista en la humillación es manifiesto, aunque escenificado.

Netlog continúa, sobre una fotografía enmarcada de una modelo que tiene en su consulta como catálogo, mostrando una vulva digna del Playboy. Una vulva "preciosa" y "bien estructurada". La proyección machista del modelo erótico está invertida, depositada en la preferencia/responsabilidad femenina, pero actuando desde el objetivismo fotográfico que coloca a la mujer segmentada en su vulva en la centralidad escópica: "Las mujeres no quieren que los labios menores se proyecten sobre los labios

\footnotetext{
${ }^{40}$ Relata la frustración de su madre y otras cineastas que rodaron documentales feministas en el pasado, ante el imparable asedio al cuerpo de la mujer por la industria cosmetológica.

${ }^{41}$ El bótox, se explica, "paraliza" los músculos de la cara. Metáfora del destino femenino. "Quizá venga bien perder" la expresividad de la cara, continúa. La fragilidad de una mujer como objeto precioso y delicado hendido/grabado/escrito y frágil (bello) traería la "rotura" o el placer del tormento aplicado en el accionar de la mirada dominante.

${ }^{42}$ Los símiles del argumento del cirujano son arañazos en la carrocería de un coche, la cosmética tradicional para mejorar la imagen como condición propia de la mujer... No está solo en esta tarea de asedio: un marido culpabiliza a su mujer cuando excusa que está perfecta y que las arrugas "sólo las ve ella"; el resto de amigas alaban las maravillas de la cirugía, y se acusan entre sí aludiendo al "hábito" consumista (de productos cosmetológicos) de "cuidarse cada día"; más adelante las redactoras de una revista de modas culpabilizan del malestar a las propias mujeres, no a las imágenes ideales que proyecta la revista, que responden a un mercado.

${ }^{43}$ La referencia correlativa a que "trabajarían menos" (tendrían menos ofertas laborales) si no se sometieran pone las cosas en un enmarcado optimismo de éxito laboral (recuérdese la denuncia de la profesionalización en la belleza de Wolf, 1991). La pacata sexualidad triunfante de Sexo en Nueva York parece un referente ingenuo.

${ }^{44}$ Del The Laser Vaginal Rejuvenation Institute of Los Angeles.

${ }^{45}$ El "cariño" del cirujano de Nip/Tuck.
} 
mayores. Los quieren ahí debajo. Eso es lo que representa esta foto. Estas fotos las han traído las mujeres. Quieren tener este aspecto. Quieren ser así, quieren ser como las chicas del Playboy". La periodista insiste en que muchas mujeres tienen los labios grandes, pero el cirujano dice "preferir" las que no los tienen: "Me gustan así". Aquí se adelanta por fin la preferencia masculina a la del médico.

El documental continúa ya en el quirófano, donde una paciente está siendo intervenida. La contradicción interrogativa desvela el mecanismo machista por la preferencia del modelo erótico de la vulva Playboy. Mientras el cirujano corta un labio menor de la paciente, la documentalista le pregunta: "Pero esas, ¿son zonas erógenas, no?". Netlog, haciéndose repetir la pregunta, contesta: "Bueno, es cierto, que se tiene sensación en esta zona; pero nadie jamás se ha quejado de que haya perdido la sensibilidad, o de que esta intervención haya reducido el placer sexual". El aumento de la excitación sexual femenina ${ }^{46}$ estaría confiándose al sentimiento de ser más deseada. La aserción apropiativa del cirujano se ampara en el mercado: "Esta técnica sólo la practico yo, es exclusivamente mía, es mi sello ${ }^{47}$ y esto está de moda. Tenemos tanta demanda que no damos abasto".

El modelo no se queda solamente en la sugerencia erótica, sino que supone la performance pornográfica. Una paciente de 15 años relata en el mismo lugar la necesidad de estos cánones, trasladados de lo erótico al porno: "Hoy día hay mucho porno; y hay gente que espera encontrar ciertas cosas. Y a veces, cuando se topan con algo que no es exactamente como lo han visto en las películas, les parece que es raro... [C]uando estoy con mi novio..., sé que me sentiría mucho mejor si yo fuera más..., como esas imágenes que he visto, como las demás". De ahí que desee modificar sus labios menores. Su madre la llevó al médico (entendiendo enfermedad o malformación) por encontrarse su hija extraña de su propia vulva. Un enajenamiento corporal provocado por el modelo de comparación, que opera de nuevo sobre la diferencia ${ }^{48}$. Sentir que la vulva es "rara" es incidir en la "rareza de la vulva". Aquella vulva dentada (Torres Ruiz, 2002; Braun y Wilkinson, 2001) de la que hasta el demonio huía en la tradición medieval. Lo orgánico siempre es excesivo (Torres Ruiz, 2002), desde luego. El reportaje es autosuficiente para dar una respuesta crítica. La documentalista observa una revista de Playboy y se pregunta frente a una modelo desnuda: "Entonces, ¿es esto lo que quieren las mujeres? Aquí no hay nada". En efecto, el pubis de la modelo está operado o retocado con Photoshop, prácticamente ausente, levemente insinuado. Velo y ensueño van de la mano. Los modelos pornográficos o eróticos de los años setenta, continúa, eran más frondosos, "con sus sexos completos", con bello, más "reales". Por último, el doctor Netlog declara que "la medicina es un negocio" y que pronto se retirará; la reportera sueña con la paranoia estético-quirúrgica, y su autoestima decae en culpabilidades autoalimentadas, que puede aliviar rodeándose de los suyos y el afecto incondicional que no la examina de continuo, pero que carece de promoción visual. La preocupación por el imparable sometimiento de la mujer hace del activismo una posibilidad, pero muy venida a menos.

Braun y Kitzinger (2001) recogen las mayores críticas hacia estas prácticas quirúrgicas, donde socialmente se entiende la vagina como problema, en su tamaño y forma, labios que, desplegados, suponen promiscuidad, suciedad, patología. La vulva aparece tras su reducción estética como inmóvil, frente a la función del pene masculino que en su movilidad se hincha y deshincha. La sexualidad femenina, además, quedaría concentrada en el clítoris (reducido) y la penetración (aumentada), obviando zonas erógenas periféricas. $Y$ todo esto en modelos de una sexualidad heterosexual. El interés por disminuir la vulva la hace "perfectible" y objeto de dominación recurrente, "recordando" la "evidencia" del dimorfismo sexual. El modelo pornográfico se recrea en el pene exhibido, la eyaculación y su visibilidad prolongada (primer plano) y en potencia eréctil (Giménez Gatto, 2007). El patrón del placer femenino queda relegado al placer masculino en el control del cuerpo mirado.

Por último, es necesario recordar una cuestión capital que subyace a estas consideraciones quirúrgicas, que trae a la condición sexo-género y sus atribuciones médicas en los denominados intersexos (Diamond y Sigmundson, 1997; crítica en Kessler, 2002, y Dreger, 1998). Aquí, la adjudicación de sexogénero se hace por medio de construcciones y reconstrucciones de vaginas y penes (Kessler, 1990; Van den Wijngaard, 1997; Gregori Flor, 2006), con afecciones psicológicas supuestas (Agramonte et al., 2007).

\footnotetext{
${ }^{46}$ El mismo documental dice que estas operaciones disminuyen más bien el placer sexual de las mujeres operadas. Algo distinto a la pérdida del placer en los trans sometidos a cambio de sexo, o en la cirugía de readscripción de sexo en infantes (Minto et al., 2003; Creighton y Minto, 2001; la crítica en Chase, 1998, y Sytsma, 2004).

${ }^{47}$ Cuando acaba, por cierto, coloca un papel con un número de intervención al lado de la vulva operada. Recordemos la performance de M. Rosler Vital statistics of a Citizen, Simply Obtained (1977).

${ }^{48}$ La chica habló y dejó grabar su operación obteniendo un descuento por el cirujano.
} 
Es notorio cómo en estas prácticas se da por hecha la dualidad correlativa del sexo=género, que debe ser "mejorada" técnicamente para adecuarla a una realidad natural. Esta naturalización por la técnica quirúrgica asume por tanto la existencia de estados intersexo por encima de los inter-, multi- o transgénero. Es así como se construyen neovaginoplastias a partir de la descripción anatómica de la agenesia de vagina (García Bernal et al., 2001). Este furor por la adecuación, la medición, la simetría, en fin, se hace evidente cuando los cirujanos apenas pueden dar cuenta de los motivos de la variabilidad corporal por fuera de la normatividad estadística (objetivización estética), por ejemplo, en la hipertrofia, acabando por referir cuestiones más que dudosas: iatrogénicas o culturales a partir del concepto inherente de patología (Sanjuán Rodríguez et al., 2009: 110).

\section{Conclusiones y perspectivas}

La profusión quirúrgica lleva a reductos post-raciológicos y genéricos, pero quizá no tanto post-sexuales. Que ésta fuera la última frontera estaría por ver. Parece dudoso, atendiendo no sólo a la tecnología farmacológica sobre el apetito sexual y las intervenciones quirúrgicas, antequirúrgicas y biocorporales en los aparatos sexuales, o al cibersexo y afines, sino a la evolución post-pornográfica en su visibilidad estética (Giménez Gatto, 2007). Empero, la raza, el género, la clase, se doblegan ante la cuestión sexual y promocional, donde una parte del feminismo puede arraigar excusando la cirugía como recurso emancipador (Tait, 2007). La cirujana francesa Suzanne Noël (La Chirurgie Esthétique, son rôle social, Paris, 1926) practicó la cirugía estética hasta 1954, manifestándose como ardiente feminista y defendiendo la promoción laboral por estos medios (Regnault y Stephenson, 1971; Blair, 1976; Glicenstein, 1988; Davis, 1999). Muchas mujeres, en fin, como acontece con los debates sobre la prostitución (en qué casos es coactiva o no) desean expresar su decisión individual adquiriendo poder y libertad por medio de un medio expresivo y promocional como es la cirugía (Davis, 1995; Moreno Álvarez, 2009). Resulta de la asunción femenina de la tecnología como poder. Sin embargo, queda pendiente la superación del concepto de Humanidad en las posibilidades tecnomédicas, que debe resolverse en términos no bioéticos, sino sociales, económicos y políticos.

\section{Referencias bibliográficas}

Afshari R. y Bhopal, R. (2002): "Changing pattern of use of ethnicity and race in scientific literature", International Journal of Epidemiology, 31: 1074-1076.

Agramonte, A. et al. (2007): "Cirugía genital: impacto psicológico y sexual. Presentación de una paciente", Revista cubana de Endocrinología, 18(2): s. p.

Álvarez Degregori, M. C. (2001): Sobre la mutilación genital femenina y otros demonios. Barcelona: U. A. B.

Arquiola, E. (1978): "Topinard: médico y antropólogo físico", Asclepio, XXX-XXXI: 41-61.

Balsamo, A. (1996): Technologies of the Gendered Body. Durham: Duke University Press.

Baudouin, J. Y. y Tiberghien, G. (2004): "Symmetry, averageness, and feature size in facial attractiveness of women", Acta Psychologica, 117(3): 313.

Blair, O. R. (1976): "The Development of Aesthetic Plastic Surgery: A History", Aesthetic Plastic Surgery, 1: 3-24.

Bleier, R. ed. (1988): Feminist Approaches to Science. NY: Pergamon Press.

Bourdieu, P. (1998): La distinción. Criterio y bases sociales del gusto. Madrid: Taurus.

Braun, V. y Kitzinger, C. (2001): "The perfectible vagina: size matters", Culture, Health \& Sexuality, 3 (3): 263277.

Braun, V. y Wilkinson, S. (2001): "Socio-Cultural Representations of the Vagina", Journal of Reproductive and Infant Psychology, 19: 17-32.

Canto Vidal, et al. (2006): "Rinoescultura", Revista electrónica de las Ciencias Médicas en Cienfuegos. Medisur, 4 (2): 24-29.

Caplan, A. L. ed. (1978): The Sociobiology Debate: readings on ethical and scientific issues. New York: Harper \& Row.

Caro Baroja, J. (1995): Historia de la Fisiognómica. El rostro y el carácter. Madrid: Istmo. 
Casa, O. (2007): "Trasplante de tejido facial. Aspectos jurídicos", Cirugía Plástica, 17 (1): 31-48.

Chase, C. (1998): "Surgical Progress Is Not the Answer to Intersexuality", The Journal of Clinical Ethics, 9 (4): 385-392.

Clarke, A. y Butler, P. E. M. (2005): "Facial transplantation: Adding to the reconstructive options alter severe facial injury and disease", Expert. Opin. Biol. Ther., 5: 1.

Córdoba, M. (2010): "La cirugía estética como práctica sociocultural distintiva: un lacerante encuentro entre corporeidad e imaginario social", Revista Latinoamericana de Estudios sobre Cuerpos, Emociones y Sociedad, 2 (2): 37-48.

Creighton, S. y Minto, C. (2001): "Managing intersex", Editorials, BMJ, 323: 1264-1265.

Daniel, R. K. (1992): "The nasal Tip: Anatomy and aesthetics", Plast. Reconstr. Surg., 89: 216.

Davis, K. (1995): Reshaping the Female Body: The Dilemma of Cosmetic Surgery. Londres: Routledge.

- (1999): "Cosmetic surgery in a different voice: The case of madame Noël", Women's Studies International Forum, 22 (5): 473-488.

De Lauretis, T. (1984): Alice Doesn't: Feminism, Semiotics, Cinema. Bloomington: Indiana U. Press.

- (2007): El cuerpo a la carta. Estudios culturales sobre cirugía cosmética. México: La Cifra.

Desfilis, E. y Font, E. (2001): "Entrevista a Randy Thornhill", Anuario 2001 de la Universidad de Valencia: s. p.

Diamond, M. y Sigmundson, M. D. (1997): "Sex reassignment at birth: lomg-term review and clinical implications", Arch. Pediatr. Adolesc. Med., 151: 298-304.

Díaz Rojo, J. A. y Morant Marco, R. (2008): "Persuasión lingüística, salud y belleza", Espéculo. Revista de estudios literarios, 38: s. p.

Dreger, A. D. (1998): Hermaphrodites and the Medical Invention of Sex. Cambridge: Hardvard U. Press.

Duarte y Sánchez, A. et al. (2005): "Rinoplastia abierta para la nariz mestiza", Cirugía Plástica, 15 (2): $94-99$.

Edgar, A. (2009): "The Challenge of Transplants to an Intersubjectively Established Sense of Personal Identity", Health Care Anal., 17 (2): 123-133.

Falces, E. et al. (1970): "Cosmetic Surgery of the non-caucasian nose", Plast. Reconstr. Surg., 45: s. p.

Farkas, L. G. y Kolar J. C. (1987): "Anthropometrics and art in the aesthetics women's faces", Clin. Plast. Surg., 14: 599.

Farkas, L. G. et al. (1985a): "Vertical and horizontal proportions of the face in young adult North American Caucasians: Revision of neoclassical canons", Plast. Reconst. Surg., 75: 328.

- (1985b): "Inclinations of the facial profile: Art versus reality", Plast. Reconst. Surg., 75: 509.

Flowers, R. S. (1977): "The surgical correction of the non-caucasian nose", Clin. Plast. Surg., 4: s. p.

Gálvez Chávez, J. C. (2005): "Rinoplastia abierta, experiencias en el Hospital Clinicoquirúrgico 'Hermanos Ameijeiras' (1997 a 2005)", Rev. Cub. Cirug., 44 (4): s. p.

Gálvez Chávez, J. C. y Millán, Y. J. (2007): "Cambios antropométricos en la nariz mestiza después de rinoplastia abierta", Rev. Cubana Cir., 46 (4): s. p.

García Bernal, F. J., et al. (2001): "Vaginoplastia con técnica de los colgajos de Málaga", Actualidad Obstétrico Ginecológica, XIII (5): 195-199.

Giddens, A. (1994): Modernidad e identidad del yo: el yo y la sociedad en la época contemporánea. Barcelona: Península.

Gilman, S. L. (2001): Making the Body Beautiful. A Cultural History of Aesthetic Surgey. Princenton and Oxford: P. U. P.

Giménez Gatto, F. (2007): "Pospornografía", Estudios visuales 5. Ensayo, teoría y crítica de la cultura visual y el arte contemporáneo, Monográfico "24/7: Políticas de la visualidad en un mundo 2.0": 95-105.

Glicenstein, J. (1988): "Pioneers in plastic surgery. Suzanne Noël (1878-1954)", Ann. Chir. Plast. Esthet., 33 (4): 389-94.

Goffman, E. (2003): Estigma. La identidad deteriorada. Madrid: Amorrortu.

González, E. (2003): "The importance of Race and Ethnic Background in Biomedical Research and Clinical Practice", New England of Medicine, 348: 1170-5.

Gónzalez Cortés, Ma. T. (2001): "La moda, ese cuerpo imaginario", en Azpeitia M. et al. eds.: Piel que habla. Viaje a través de los cuerpos femeninos: 175-204. Barcelona: Icaria.

Good, B. J. (2003): Medicina, racionalidad y experiencia. Una perspectiva antropológica. Barcelona: Bellaterra.

Goodman, M. (2009): “Female Cosmetic Genital Surgey”, Obstetrics \& Gynecology, 113 (1): 154-159. 
Gregori Flor, N. (2006): "Los cuerpos ficticios de la biomedicina. El proceso de construcción del género en los protocolos médicos de asignación de sexo en bebés intersexuales", AIBR. Revista de Antropología Iberoamericana, 1 (1): 103-124.

Gutiérrez De Aguas, R. (2004): Estudio de la relación entre características antropométricas, atractivo facial y calidad seminal. Valencia: Universitat de València. [Tesis Doctoral]

Gutiérrez De Aguas, R. et al. (2005): "El atractivo facial masculino como predictor de la calidad seminal", Zainak, 27: 319-330.

Habermas, J. (2002): El futuro de la naturaleza humana. ¿Hacia una eugenesia liberal? Barcelona: Paidós.

Haiken, E. (1997): Venus envy: A history of cosmetic surgery. Baltimore y Londres: John Hopkins U. Press.

Halberstam, J. y Livingston, I. eds. (1995): Posthuman Bodies. Bloomington: Indiana U. Press.

Hanabusa, M. (2008): "Reading Dual Meanings of Power on Young Women's Bodies: The Representation of Cosmetic Surgery in Japanese Manga", International Research in Children's Literature, 1: 82-98.

Harris, M. (2000): Teorías sobre la cultura en la era posmoderna. Barcelona: Crítica.

Hernández Piñero, A. (2006): “¿Nuevas tecnologías, viejos dualismos? Reflexiones sobre el cuerpo y la diferencia sexual en la tecnocultura", XLIII Congreso de Filósof@s Jóvenes. Filosofía y Tecnología(s). Palma de Mallorca: s. p.

Imaz, E. (2006): "La maternidad en el seno de las parejas lesbianas", Arxius de Ciències Socials, 15: 89-100.

Iranova, A. (2012): Facing Japaneseness: Becoming the Ethnic Other through Gyaru Self-Transformations. Amsterdam: University of Amsterdam. [Research Master's Thesis].

Jay, M. (2003): Campos de fuerza. Entre la historia intelectual y la crítica cultural. Buenos Aires: Paidós.

- (2007): Ojos abatidos. La denigración de la visión en el pensamiento francés del siglo XX. Madrid: Akal.

Johnston, V. S. et al. (2003): "Human facial beauty. Current theories and methodologies", Arch. Facial Plast. Surg, 5: 371.

Kessler, S. J. (1990): "The Medical Construction of Gender: Case Management of Intersexed Infants", Signs, 16 (1): 3-26.

- (2002): Lessons from the Intersexed. New Brunswick: Rutgers University Press.

Langlois, J. H. et al. (2000): "Maxims or myths of beauty? A meta-analytic and theoretical review", Psychological Bulletin, 126 (3): 390.

Langlois, J. H. y Roggman, L. A. (1990): "Attractive faces are only average", Psychological Science, 1: 115.

Laurence, M. M. et al. (1996): "Anthropometric analysis of the female latino nose. Revised aesthetic concepts and their surgical implications", Arch. Otolaryngol. Head Neck Surg., 122: 1079-1086.

Lévi-Strauss, C. (1985): La mirada alejada. Madrid: Argos Vergara.

- (1993): Raza y Cultura. Madrid: Cátedra.

Lewontin, R. C. y Kamin, L. J. (1996): No está en los genes. Crítica del racismo biológico. Barcelona: Grijalbo.

MacGregor, F. C. (1967): "Social and Cultural Components in the Motivations of Person Seeking Plastic Surgery of the Nose", J. Health Soc. Behav., 8(2): 125-35.

Magro, A. M. (1999): "Evolutionary-derived anatomical characteristics and universal attractiveness", Percept. Mot. Skills., 88: 147-166.

Martínez Lirola, M. (2010): "Explorando nuevas formas de violencia de género: la mujer como objeto en los folletos de clínicas de estética", Global Media Journal Mexico, 7(13): 80-94.

Martínez-Pereda Rodrígues, J. M. (1997): La cirugía estética y su responsabilidad. Granada: Comares.

Matory, W. E. y Falces, E. (1986): "Non-caucasian rhinoplasty: a 16-year experiencie", Plast. Reconstr. Surg., 77: 239-252.

McCarthy, J. G. y Wood-Smith, D. (1992): "Rinoplastia", en McCarthy, J. G.: Cirugía plástica. La cara: II, cap. 6. Buenos Aires: Ed. Médica Panamericana.

Miller, L. (2004): "Youth fashion and changing beautification practices", en Mathews, G. y White, B. eds.: Japan 's Changing Generations. Are young people creating a new society? cap. 5. London: Routledge Curzon.

Minto, C. L. et al. (2003): "The effect of clitoral surgey on sexual outcome in individuals who have intersex conditions with ambiguos genitalia: a cross-sectional study", Lancet, 361: 1252-1257.

Moreno Álvarez, A. (2009): Deconstrucción literaria de los trastornos de la alimentación y de la cirugía estética en las novelas de Margaret Atwood y Fay Weldon. Oviedo: Universidad de Oviedo. [Tesis doctoral]. 
Mulvey, L. (1991): "Visual Pleasure and Narrative Cinema", en Warhol, R. R. y Herndl D. P. eds.: Feminisms: An Anthology of Literary Theory and Criticism: 432-442. New Brunswick, N. J.: Rutgers U. Press.

Muñiz, E. (2010): Transformaciones corporales: la etnocirugía. Barcelona: UOC.

Nieto, J. A. (1998): "Transgénero/Transexualidad: de la crisis a la reafirmación del deseo", en Nieto, J. A. comp.: Transexualidad, Transgenerismo y cultura: 11-37. Madrid: Talasa.

Ohmori, K. (1992): "Cirugía estética en el paciente asiático", en McCarthy, J. G.: Cirugía plástica. La cara: II, cap. 18. Buenos Aires: Ed. Médica Panamericana.

O'neill, H. y Godden, D. (2009): "Ethical Issues of Facial Transplantations", British J. of Oral and Maxillofacial Surg., 47 (6): 443-445.

Ortiz Monasterio, J. F. (1977): "Rhinoplasty on the 'mestizo' nose", Aesthet. Plast. Surg., 4: 189-194.

- (1986): Rinoplastia. La nariz no indoeuropea. México: Ed. Médica Panamericana.

Ortiz Monasterio, J. F. y Olmedo, A. (1977):"Rhinoplasty on the mestizo nose", Clin. Plast. Surg., 4: 189-194.

Pardo, J. et al. (2006): "Laser labioplasty of labia minora", International Journal of Gynecology \& Obstetrics, 93 (1):38-43.

Pérez Froiz, M. y Currais Porrúa, J. (1991): "El determinismo biológico como ideología legitimizadora del patriarcado: el caso de la sociobiología", en Actas de las terceras jornadas de coeducación. La enseñanza de las matemáticas y las ciencias naturales: 25-30. Valencia: Generalitat Valenciana.

Perrett, D. I. et al. (1994): "Facial shape and judgements of female attractiveness", Nature, 368 (6468): 239.

Preminger, B. (2001): "The Jewish Nose and Plastic Surgery: Origins and Implications", JAMA, 286: 2161.

Puig-Samper, M. A. y Galera, A. (1983): La antropología española del siglo XIX. Madrid: CSIC.

Quaglio, C. (2007): "El cuerpo X. Extreme Makeover, un reality show de cirugías estéticas", Question, 1(13): s. p.

Ramírez, O. M. (2007): "El ojo hermoso". Cirugía plástica ibero-latinoamericana, 33 (2): s. p.

Rangel Audelo, R. y Rodríguez Perales, M. A. (1999): "Manejo de la nariz mestiza mediante injertos en la punta nasal. Presentación de 45 casos", Rev. Sanid. Milit. Mex., 53 (3): 188-197.

Rees, T. D. (1969): "Nasal plastic surgery in the Negro", Plast. Reconstr. Surg., 43: 13.

Regnault, P. y Stephenson, K. L. (1971): "Dr. Suzanne Noël. The first woman to do esthetic surgery", Plast. Reconstr. Surg., 48 (2): 133-139.

Rhodes, G. et al. (1998): "Facial symmetry and the perception of beauty", Psychonomic Bulletin and Review, 5: 659.

Ricketts, R. M. (1982): "Divine proportion in facial esthetics", Clin. Plast. Surg., 9: 401.

Romo, T. y Abraham, M. T. (2003): "The ethnic nose", Facial Plast. Surg., 19 (5): 269-278.

Sahlins, M. (1982): Uso y abuso de la biología. Madrid: Siglo XXI.

Saletti Cuesta, L. (2008): "Propuestas teóricas feministas en relación al concepto de maternidad", Clepsydra, 7: 169-183.

Sanjuán Rodríguez, S. et al. (2009): "Hipertrofia de labios menores en la pubertad", Cir. Pediatr., 22: 109111.

Santiso Sanz, R. (2001): "El cuerpo del delito. Torturas culturales en torno al cuerpo", en Azpeitia M. et al. eds.: Piel que habla. Viaje a través de los cuerpos femeninos:223-244. Barcelona: Icaria.

Sastré, N. (2007): "El porqué de un trasplante facial", Cirugía Plástica, 17 (1): 49-54.

Schiebinger, L. (1987): "The History and Philosophy of Women in Science", Signs, 12 (2): s. p.

- (1993): Nature's Body. Gender ín the Making of Modern Science. Boston: Beacon Press.

Schwartz, R. S. (2001): "Perfil racial en investigaciones médicas", N. Engl. J. Med., 344: 1392-3.

Soley-Beltrán, P. (2012): "Muñecas que hablan. Ética y estética de los modelos de belleza en publicidad y moda", Revista de Dialectología y Tradiciones Populares, 67 (1): 115-146.

Sytsma, S. (2004): "Ethical dilemmas in retrospective studies on genital surgey in the treatment of intersexual infant", Cambridge Quarterly of Healthcare Ethics, 13: 394-403.

Tait, S. (2007): "Television and the domestication of Cosmetic Surgery", Feminist Media Studies, 7 (2): 119 135.

Thornhill, R. (1998): "Darwinian aesthetics", en Crawford, C. y Krebs, D. eds.: Handbook of Evolutionary Psychology: Ideas, Issues and Applications: 543-572. New Jersey: Erlbaum.

Thornhill, R. y Gangestad, S. W. (1999): "Facial attractiveness", Trends Cogn. Sci, 3: 452-460.

Torres Ruiz, M. A. (2002): "Sexo inorgánico en el ciberespacio: relaciones entre ciencia y pornografía", Desacatos. Saberes y razones, s. d.: 23-56. 
Vale Nieves, O. (2006-2007): "El cuerpo del Delito/Deleite", Teknokultura, 6: s. p.

Van Den Wijngaard, M. (1997): Reinventing the Sexes: The Biomedical Construction of Femininity and Masculinity. Bloomington: Indiana U. Press.

Vanegas, L. J. et al. (2008): "Consideraciones acerca del uso de la variable etnia/raza en investigación epidemiológica para la Salud Pública: A propósito de investigaciones en inequidades", Rev. Méd. Chile, 136: 637-644.

Vecter, F. y Hage, J. J. (1997): "Clinical Anthropometry and Canons of the Canons of the Face in Historical Perspective", Plast. Reconstr. Surg., 106: 1090.

VV.AA. (1989): "Paul Topinard (1830-1911)", International Journal of Anthropology, 4 (4). [Monográfico].

Wen, J. C. (1921): "Ontogeny and Phylogeny of the nasal cartilages", Cont. Embryol. Carnegie Institution, 414: 109.

Whitaker, L. A. y Pertschuk, M. (1982): "Facial skeletal contouring for aesthetic purposes", Plast. Reconstr. Surg., 69: 245.

Wieviorka, M. (2003): "Diferencias culturales, racismo y democracia", en Mato, D. coord.: Políticas de identidades y diferencias sociales en tiempos de globalización: 17-32. Caracas: FACES-UCV.

Wolf, N. (1991): El mito de la belleza. Barcelona: Emecé.

\section{Breve CV del autor}

Santiago Martínez-Magdalena es Doctor en Filosofía-Antropología Social y Cultural por la Universidad Nacional de Educación a Distancia. En la actualidad es profesor asociado en la Universidad de Murcia. Sus principales líneas de investigación son la antropología de cuerpo y la antropología y la memoria. 